\title{
Chen Jingrun, China's famous mathematician: devastated by brain injuries on the doorstep to solving a fundamental mathematical puzzle
}

\author{
Ting Lei, MD, ${ }^{1}$ Evgenii Belykh, MD, ${ }^{1}$ Alexander B. Dru, BA, ${ }^{2}$ Kaan Yagmurlu, MD, ${ }^{1}$ \\ Ali M. Elhadi, MD, ${ }^{1}$ Peter Nakaji, MD, ${ }^{1}$ and Mark C. Preul, MD ${ }^{1}$ \\ 1Department of Neurosurgery, Barrow Neurological Institute, St. Joseph's Hospital and Medical Center, Phoenix; and 2University \\ of Arizona College of Medicine, Tucson, Arizona
}

\begin{abstract}
Chen Jingrun (1933-1996), perhaps the most prodigious mathematician of his time, focused on the field of analytical number theory. His work on Waring's problem, Legendre's conjecture, and Goldbach's conjecture led to progress in analytical number theory in the form of "Chen's Theorem," which he published in 1966 and 1973. His early life was ravaged by the Second Sino-Japanese War and the Chinese Cultural Revolution. On the verge of solving Goldbach's conjecture in 1984, Chen was struck by a bicyclist while also bicycling and suffered severe brain trauma. During his hospitalization, he was also found to have Parkinson's disease. Chen suffered another serious brain concussion after a fall only a few months after recovering from the bicycle crash. With significant deficits, he remained hospitalized for several years without making progress while receiving modern Western medical therapies. In 1988 traditional Chinese medicine experts were called in to assist with his treatment. After a year of acupuncture and oxygen therapy, Chen could control his basic bowel and bladder functions, he could walk slowly, and his swallowing and speech improved. When Chen was unable to produce complex work or finish his final work on Goldbach's conjecture, his mathematical pursuits were taken up vigorously by his dedicated students. He was able to publish Youth Math, a mathematics book that became an inspiration in Chinese education. Although he died in 1996 at the age of 63 after surviving brutal political repression, being deprived of neurological function at the very peak of his genius, and having to be supported by his wife, Chen ironically became a symbol of dedication, perseverance, and motivation to his students and associates, to Chinese youth, to a nation, and to mathematicians and scientists worldwide.
\end{abstract}

http://thejns.org/doi/abs/10.3171/2016.2.FOCUS1595

KEY WORDS brain trauma; Chen Jingrun; Chinese Cultural Revolution; Goldbach's conjecture; history of neurosurgery; Parkinson's disease

$\mathrm{C}$ HEN Jingrun (Fig. 1), one of the world's greatest mathematicians, focused on the field of analytical number theory. Although he made significant advancements on Waring's problem (Edward Waring, 17361798) and Legendre's conjecture (Adrien-Marie Legendre, 1752-1833), he is best known for "Chen's Theorem," a significant step in his work on the search for a solution to Goldbach's conjecture, posited by the German (Prussian) mathematician Christian Goldbach (1690-1764). In 1966 and 1973, Chen published two papers to explain that every sufficiently large even integer can be written as the sum of a prime and a semiprime. ${ }^{7,8}$ Chen's work proved to be a milestone in the study of Goldbach's conjecture, one of the oldest unsolved mathematical problems, and in number progression theory in general. Chen's anxiously await- ed next announcement to the scientific and mathematics communities was to be a full solution of Goldbach's conjecture, but an unfortunate series of brain injuries altered his life and substantially affected the science of mathematics and Chinese education.

\section{Chen's Early Life}

Chen Jingrun was born on May 22, 1933, in Fuzhou, Fujian Province, China, during a period of Chinese civil war. His father, Chen Yuanjun, was a post office clerk and his mother cared for the family. Chen's family consisted of 12 children, only 6 of whom currently survive. Chen was the third child of his family, which lived on a meager income. Although poor, Chen's parents sought to provide 


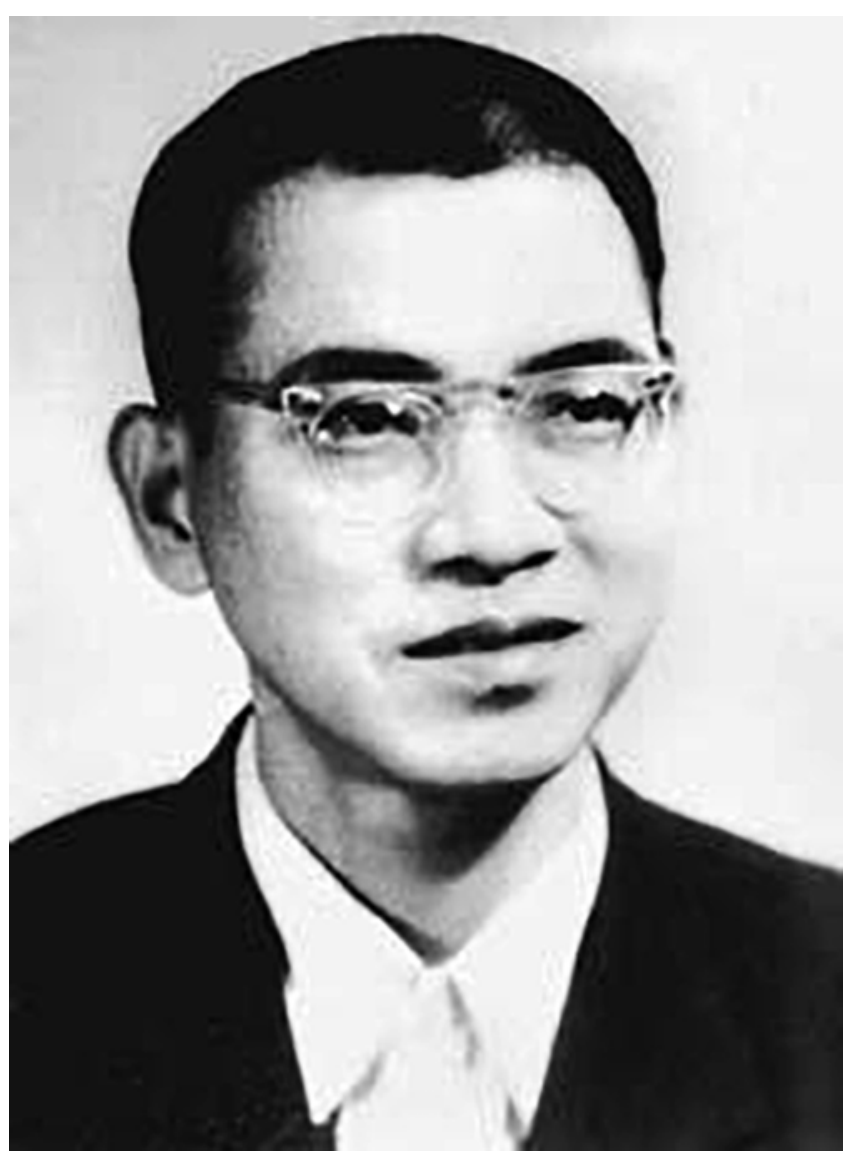

FIG. 1. Chen Jingrun (May 22, 1933-March 19, 1996) during his early academic years.

and instill the traditional strong tenets of perseverance in all aspects of life, as they struggled to send their children to school and obtain even basic health care. ${ }^{9}$

On July 7, 1937, war erupted with the Chinese War of Resistance against Japan, also known as the Second SinoJapanese War. By October 26, 1937, the invading Japanese army had advanced to occupy the Golden Gate after moving across the Strait of Taiwan in a prelude to the invasion of Fujian. At that time, Chen's father, Chen Yuanjun, was deployed to be a director of the Sanyuan County post office, which was set up in an old temple in the nearby mountains.

The next 8 years in Fuzhou were marked by the horrors of unrelenting conflicts and foreign military occupation. On April 21, 1941, and September 27, 1944, Japan made aggressive moves in the Fujian Province that were characterized by multiple bombing campaigns that ravaged the civilian populace. These raids also resulted in vast destruction of public and personal property and the enslavement of survivors. Natives who could escape the concentration camps established for survivors fled to the mountains where Chen lived. Thousands of refugees were quickly followed by the Japanese soldiers, and this haven was soon taken over by the Japanese, who interrogated and tortured most of the inhabitants. The horrific memories and sights that Chen experienced as a young child caused him significant traumatic emotional stress; Chen often spoke of being plagued by lifelong panic attacks and flashbacks to these events. It was not until September 9, 1945, that the Japanese troops in China (excluding Manchuria) formally stopped their military actions in the region.

Chen's childhood continued to be a struggle, even in the relative sanctuary of elementary school. He was frequently bullied and beaten by classmates who picked on him because of his thin, weak stature. As if life was not hard enough, Chen lost his mother in 1947 to tuberculosis when he was 13 years old. Chen began to find solace in his studies, particularly mathematics, where he was happiest when working on tedious algebraic equations.

After the occupation ended, Chen returned to Fuzhou with his family and started his formal education at Sanyi Middle School. In 1948, Chen was admitted to Fuzhou Yinghua High School. Here, he met his mathematics teacher, Shen Yuan, who also was a director of the Aviation Department of Tsinghua University. Shen was a knowledgeable and passionate teacher known to mix his teachings with concrete applications to foster interest and appreciation for the esoteric topics covered in his class. One day, Shen lectured on a famous number theory problem in his class called Goldbach's conjecture. Chen recounted his teacher's vivid description of the significance of the problem: "Mathematics is the science of the queen, number theory is the crown of mathematics, and Goldbach's conjecture is the pearl on the crown." Playfully, Shen told his students that he dreamt that one of them would prove the conjecture. Everyone laughed except Chen. On December 18, 1989, Chen published a memoir for The Daily Worker newspaper and stated, "I did not laugh, did not dare to laugh. I was worried my classmates would know my vision. But I never forgot this lesson to always remember the pearl on the crown and to never forget my aspirations or ideals." 22

Goldbach's conjecture, one of the oldest and most famous unsolved problems in number theory and mathematics, was created by Goldbach, and proposed in a series of letters in June 1742 to Leonhard Euler (Fig. 2). The Goldbach conjecture states simply that all positive even integers of 4 or more can be expressed as the sum of 2 primes. The set of integers are numbers that can be written without a fractional component, consisting of zero, the natural numbers, and the additive inverses of natural numbers. A prime number is a natural number greater than 1 that has no positive divisors other than 1 and itself. For example, 3 is a prime number because its only positive divisors are 1 and 3; 4 is not a prime number because 4 has 1,2, and 4 as positive divisors, not just 1 and 4 .

On June 7, 1742, Goldbach wrote to Euler proposing that every integer that can be written as the sum of 2 primes can also be written as the sum of as many primes as one wishes, until all terms are units. Goldbach then proposed a second conjecture in the margin of his letter, that every integer greater than 2 can be written as the sum of 3 primes. He considered 1 to be a prime number, a convention subsequently abandoned. The 2 conjectures are now known to be equivalent, but this did not seem to be an issue at the time. A modern version of Goldbach's marginal conjecture states that every integer greater than 5 can be 


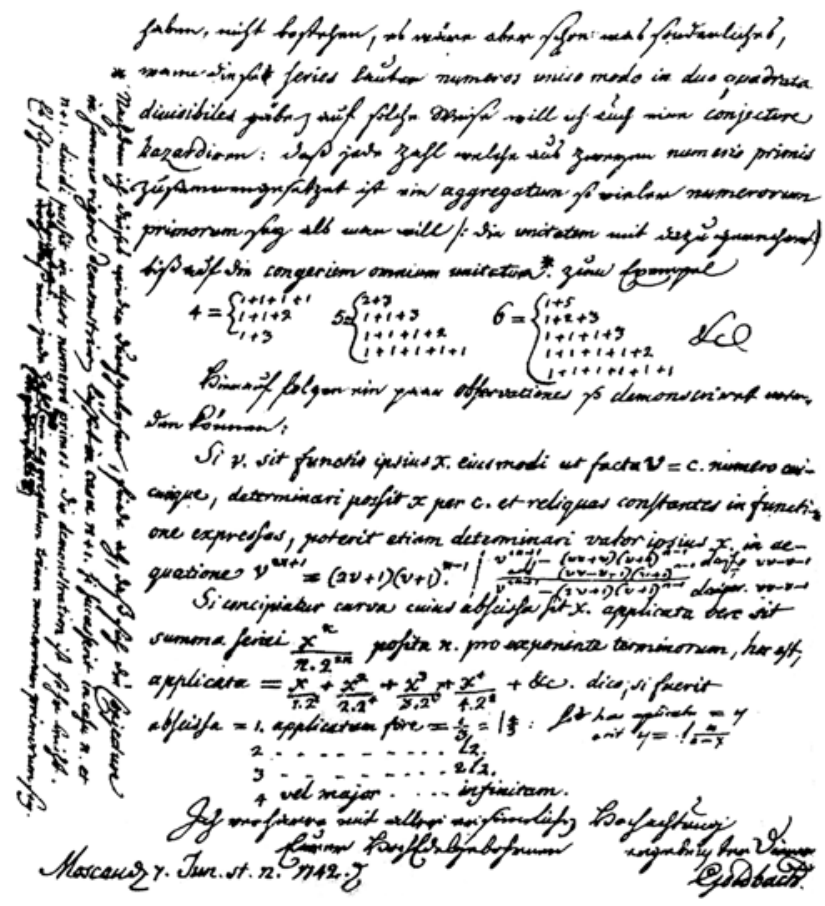

FIG. 2. The first in a series of letters from Goldbach (apparently sent from Moscow) to Leonhard Euler dated June 7, 1742, in which Goldbach suggested a conjecture that every integer that can be written as the sum of 2 primes can also be written as the sum of as many primes as one wishes. In the margin of the letter, Goldbach added that every integer greater than 2 can be written as the sum of 3 primes. Euler's response letter of June 30, 1742, states, "Dass aber ein jeder numerus par eine summa duorum primorum sey, halte ich für ein ganz gewisses theorema, ungeachtet ich dasselbe nicht demonstriren kann." "Every even integer is a sum of 2 primes, I regard as a completely certain theorem, although I cannot prove it."). Reference source for letters: http://euler archive.maa.org/correspondence/correspondents/Goldbach.html. Image source: http://commons.wikimedia.org/wiki/File:Letter_Goldbach-Euler. jpg.

written as the sum of 3 primes. As the correspondence progressed during the month, a more comprehensive version of Goldbach's conjecture emerged. In a letter dated June 30, 1742, Euler reminded Goldbach of an earlier conversation they had in which Goldbach remarked that his original conjecture followed from the statement that every even integer greater than 2 can be written as the sum of 2 primes, which is also a conjecture of Goldbach. Euler wrote that he was certain that every even integer is a sum of 2 primes, but he could not prove it. ${ }^{2,11,20}$

Goldbach's third proposal of the conjecture (equivalent to the two other preliminary versions) is the form in which the conjecture is usually expressed today, also known as "strong conjecture." The strong Goldbach conjecture implies a "weak" conjecture that all odd numbers greater than 7 are the sum of 3 odd primes. This "weak conjecture" appears to have been proved in recent work by H. A. Helfgott (http://arxiv.org/abs/1205.5252; http://arxiv.org/ abs/1305.2897). In its current form, the conjecture states that every even integer greater than 2 can be expressed as the sum of 2 primes. Despite considerable effort, the "strong" conjecture remains unsolved.

\section{Chen's Academic Life}

In 1949, Chen (Fig. 3 left) was admitted to the Mathematical Physics Department of Xiamen University. Chen self-describes his 3-year stint at the university as his "golden period," focusing on his mathematics studies. Acquaintances remember Chen appearing on the Xiamen University campus in a black student uniform with a black cap, rubber shoes, carrying a small rattan box and bedroll; his brother, a Xiamen law student, gave Chen his coat to keep warm. Xiamen Professor of Mathematics Ha Fang Zhi related that Chen's study and life in the university was one of poverty "but [he was] obsessed with school." Members of Chen's mathematics alumni fraternity put it this way: while science is like mountain climbing, some people climb the mountain, browse the scenery at the peak, and then satisfied, return to the base; while Chen's trek was not the same, he did not go back down, but instead continued to explore other paths for climbing.

Upon Chen's graduation in 1953, the Chinese government arranged for him to be a mathematics teacher at a Beijing middle school. Soon upon arriving, Chen came under fire because of his slurred speech and was forbidden from teaching. A leader of the middle school complained to Wang Yanan, the director of Xiamen University, that Chen was not a good teacher, and he was thus fired from his position. Wang was surprised because of Chen's top performance at Xiamen. Wang reasoned that teaching younger students might not be suitable for Chen, so he helped Chen secure a librarian job back at Xiamen in 1955.,222

Chen was keenly interested in number theory. He read famous mathematicians' books, such as Teiji Takagi's Elementary Number Theory Lecture and Hua Lo-keng's Additive Prime Number Theory. Afterward, he believed that he could improve on some of the results of Hua's Additive
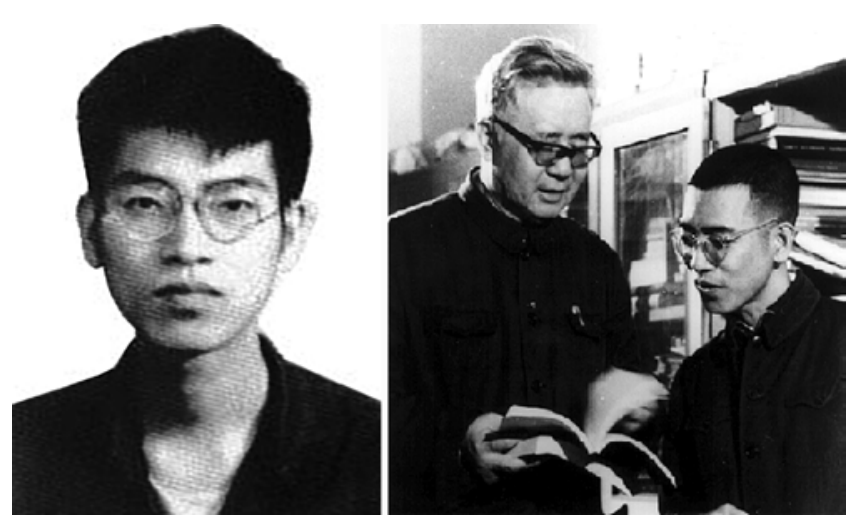

FIG. 3. Left: Chen Jingrun during his period at Xiamen University, appearing rather gaunt. Chen's extreme frugality seems to have been related to self-discipline. He lived in a room with 6 other students, and often read late into the night by flashlight. In 3 years, although the admission cost was very inexpensive, he never saw a movie, and he frequently ate only bread and pickles. Chen believed that his frugality allowed him to intensely concentrate on his studies and even may have gone so far that he considered his self-imposed poverty a contributor to his character development, to the embarrassment and chagrin, however, of his father. Right: Hua Lo-Keng (left) and Chen (right) at the start of their relationship, probably about 1956. Source: http://www.kedo.gov.cn/ story/kxjqw/360075.shtml. 
Prime Number Theory and thus wrote a prescient paper in 1956, "On Tarry's Problem," and mailed it to Hua. After reading the paper, Hua recommended that Chen join the annual meeting of the Chinese Mathematics Society held in August 1956 and give a lecture on his study of Tarry's problem. ${ }^{9}$

In August 1956, Chen attended a mathematics meeting at Xiamen University where he met his future mentor, Hua Lo-keng (Fig. 3 right). Their conversation led Hua to recognize Chen's immense talent, and he lobbied for him to become an assistant at the Institute of Mathematics, Academia Sinica, in 1957. Chen's research made great strides during his tenure at the institute, including his work on the famous circle problem, divisor problem, sphere problem, and Waring's problem. ${ }^{9}$ Additionally, Chen expounded on Hua's additive prime number theory, which so impressed Hua that he published Chen's additions to his own work in the second edition of his text. However, due to the deteriorating political atmosphere in China, especially related to anyone in science, Chen and his follow academicians were often subjected to criticism. Even in the objective world of mathematics, Chen and his associates had to be careful about the language used in publications. Identified for special political observation, he and Hua gained the nicknames "Little White Flag" and "Big White Flag," respectively. After a short leave of absence from Academia Sinica for the Dalian Institute of Chemical Physics, Chen returned in 1962 to begin working on his singular lifelong passion, proving Goldbach's conjecture.

\section{Major Mathematical Achievement}

For more than 3 years at Academia Sinica, Chen worked on an extensive (more than 200 pages) proof of Goldbach's conjecture. His colleague Min Sihe reviewed the paper carefully, and recommended modifications of his complex, tedious methods in the proof. Still, Min suggested that Chen publish the result first. Chen's thesis "On the representation of a large even integer as the sum of a prime and the product of at most two primes" was accepted in Kexue Tongbao in 1966. Unfortunately, and after having weathered the social and economic upheavals of the period of the "Great Leap Forward," what Chen believed might be a period of great progress for him was interrupted by another serious political upheaval.

Effectively beginning with the release of a document at a May 16, 1966, meeting of the Politburo in Beijing (the "May 16 Notification"), Chinese Communist Party leader Mao Zedong in the spring and summer of 1966 initiated the Great Proletarian Cultural Revolution. Commonly known as the Cultural Revolution, the movement was an extreme, aggressive, sociopolitical movement against so-called bourgeois political revisionists. Lasting in the People's Republic of China until Mao's death in 1976, the Cultural Revolution is considered to have been the darkest period for academics in China; many suffered physical torture from the brutal political repression or were killed. As the Communist Party sought to reengineer Chinese culture and politics, the upper-level educational system was attacked first: all colleges were closed, most science texts were burned (Fig. 4), and all research in universities was halted. Professors were transferred from universities to rural farming communities to work the land and manage livestock. ${ }^{18}$

At this time, Chen was forced into manual labor while living in a tiny student-type room that had been converted

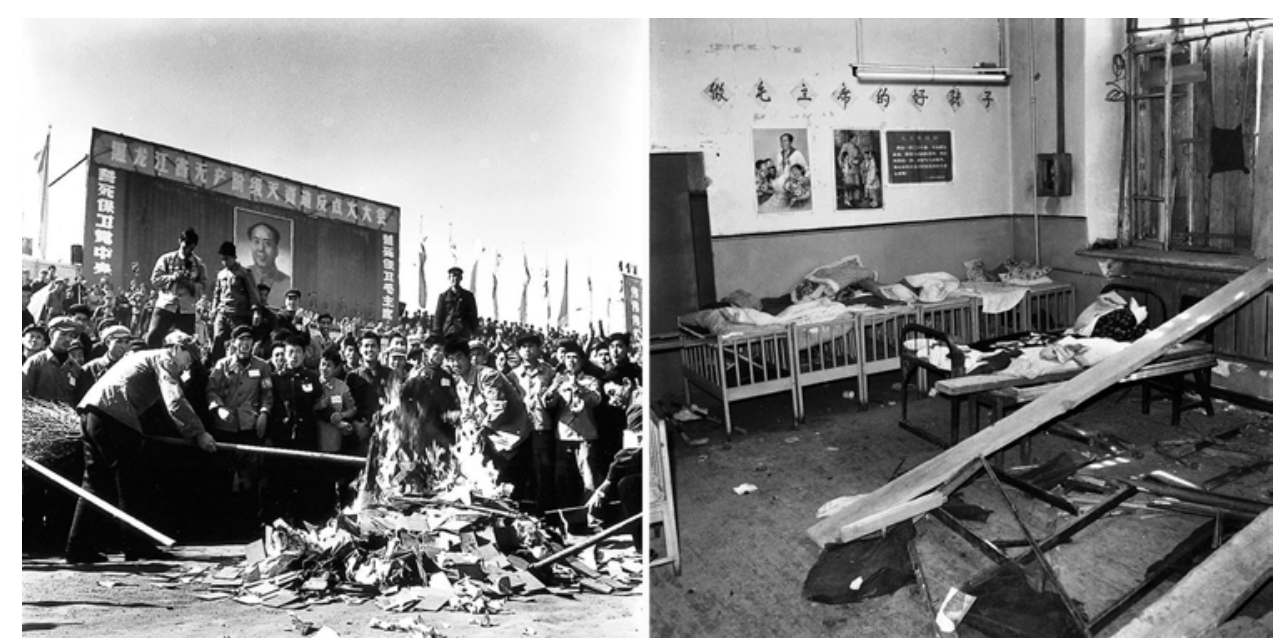

FIG. 4. Photographs from the Great Proletarian Cultural Revolution. Left: A photograph from September 1966 shows an assembly of young men, likely Red Guards, in a stadium in Heilongjiang Province burning prohibited books and other written material, as well as a woman's purse in the foreground of the pile. Any object connoting western, capitalist, or "bourgeoisie" culture was subject to confiscation and destruction, such as watches, purses, and jewelry. The top sign on the stage states: "Heilongjiang Province revolt burning assembly: Proletariat against the bourgeoisie!" The sign on the left translates as "I will protect the Party Central Committee with my life," while the slogan on the right states "I will protect Mao with my life." Right: A June 1967 photograph showing the wanton and foolish destruction of a preschool or kindergarten room, likely by Red Guards. Ironically, pictures on the wall show children with Mao, a quotation from Mao's The Little Red Book, and the characters on the wall translate to "Be good children of Mao." Photographs reprinted with permission of Li Zhensheng/Contact Press Images from the book Red Color News Soldier (Phaidon, 2003). 
from a boiler room. He had been sent to "niupeng." Niupeng, translating to "cowshed," refers to any place where prosecuted cadres and intellectuals were kept during the Cultural Revolution. It was usually not a genuine cowshed, but could be a classroom, storehouse, darkroom, temple, or stable, and the people sent to such a place were called "cow monsters" or "snake demons." There was no legal procedure for assigning someone to such a place, or for how long; a gang, loosely organized committee, or individual enforced the decisions. Many people died in such places, unable to withstand the humiliation, maltreatment, and extortion. ${ }^{15}$ Chen was constantly harassed by the newly formed young militant political activist regimen, the "Red Guards," who vigorously sought out pockets of dissent, especially among those they labeled "intellectuals" or anyone who held traditional Chinese beliefs. Chen was frequently insulted, spit on, and beaten. The attacks were often so severe that Chen would lose consciousness.

Amazingly, even under these horrible conditions, Chen kept working on his mathematics interests. However, around 1966, Chen may have attempted suicide by jumping out of a third-floor window at the institute, where he landed on a balcony of the second floor and sustained a leg injury. As more obvious and expedient targets for the Red Guards emerged, Chen was fortunately left alone and was able to secretly resume his studies, working by kerosene lamp because he was provided no electricity. Chen subsequently became chronically sick; the horrors of his life were having severe physical effects on him, perhaps even setting the scene for the beginning of his battle against tuberculosis. ${ }^{3}$

The darkness over China began to lift on September 13, 1971, when Lin Biao, the first-ranking Vice Premier of the People's Republic of China and who was a likely challenger to Mao, died in a plane crash in Mongolia. Although Lin Biao's life and service to the Cultural Revolution were celebrated by Mao, with his death came renewal of academic departments across China, including Sinica, which slowly began to start working again. The new premier of China, Zhou Enlai, took a different direction, and revalued the potentials of China's science and culture. Compared with his predecessor, he was respectful of academic science and was integral in restarting China's academic research environment.

Enthusiastically regaining his initiative after a traumatic 7-year hiatus from his work, Chen finished his modified proof for Goldbach's conjecture and sent it to Min, who reviewed the work and found no issues. After Chen passed an oral defense of his work at Sinica, in 1973 he completed his thesis "On the representation of a large even integer as the sum of a prime and a product of at most two primes." The paper outlined what is now revered as "Chen's theorem," the best advancement of Goldbach's conjecture in the world to date. Chen's theorem states that every sufficiently large even number can be written as the sum of a prime and a semi-prime. A semi-prime is the product of 2 primes. For example, $20=11+(3 \times 3){ }^{8}$

\section{Science Hero In China}

After Mao's death and the arrest of the Gang of Four, the Cultural Revolution ended in October 1976. The new Chinese government began again to stress capital and human investment in strengthening agriculture, industry, national defense, science, and technology. The official "end" of the Cultural Revolution and the refocusing of the nation's interest meant increased respect and prestige for intellectuals. Those who were viewed as promoting China's entrance into a modern world were hailed. At this time, there was a report that introduced Chen's life, work, and contributions. When his manually calculated, detailed proof was finally published and well received internationally, Chen drew the attention of Communist Party leadership, including that of Mao. ${ }^{3}$ Chen became a "science hero" in China, and his work on Goldbach's conjecture even became a topic of public interest. His images and stories of his life constantly appeared in various newspapers, books (Fig. 5), television programs, and even movies. In addition to achieving fame, Chen inspired many students to study science.

Chen's chronic health conditions, which continued to impede his activities even during this relatively stressfree period, eventually led him to his future wife. He was hospitalized in the No. 309 Liberation Army Hospital in November 1977, with admission arranged specifically by Vice Premier Deng Xiaoping. Dr. You Kun assumed Chen's care and was curious about the life of this budding national hero. As they spent more time with each other, they eventually fell in love and were married several years later on August 25, 1980, the same year Chen was elected to the Chinese Academy of Sciences. The next year marked the birth of their son, Chen Youwei.

In March 1978, because of his profound contributions to mathematics, Chen was invited to lecture at the Chinese National Science Conference (Fig. 6). Organized by the Chinese Communist Central Committee and held in Beijing, the conference was attended by China's top leaders and 6000 scientists and science administrators. Since the mid-1970s, the Party policy was to publicly support science and technology, while quietly trying to reverse much of the destruction that previous major policy initiatives, including the Cultural Revolution, had caused to China's scientific, technological, and industrial progress. The "New Long March" was the program that would promote science and technology to create a modern socialist society within 20 years. Vice Premier Deng Xiaoping's address to the conference emphasized that scientific advancement and scientists were critical for China's progress and that political victimization of scientists was harmful. Deng stated, "The crux of the Four Modernizations is the mastery of modern science and technology. Without the high-speed development of science and technology, it is impossible to develop the national economy at a high speed."10,12,17

China's scientists would be given wide access to foreign knowledge through greatly expanded international scientific and technical exchanges. It was through such reformative policy, and especially with the support of Deng for Chinese-American scientific exchange programs, that Chen was invited to conduct advanced studies at Princeton University for 5 months. He lectured and received enthusiastic approval from his peers in 1979 and that same year published a singular paper, "The smallest primes in 


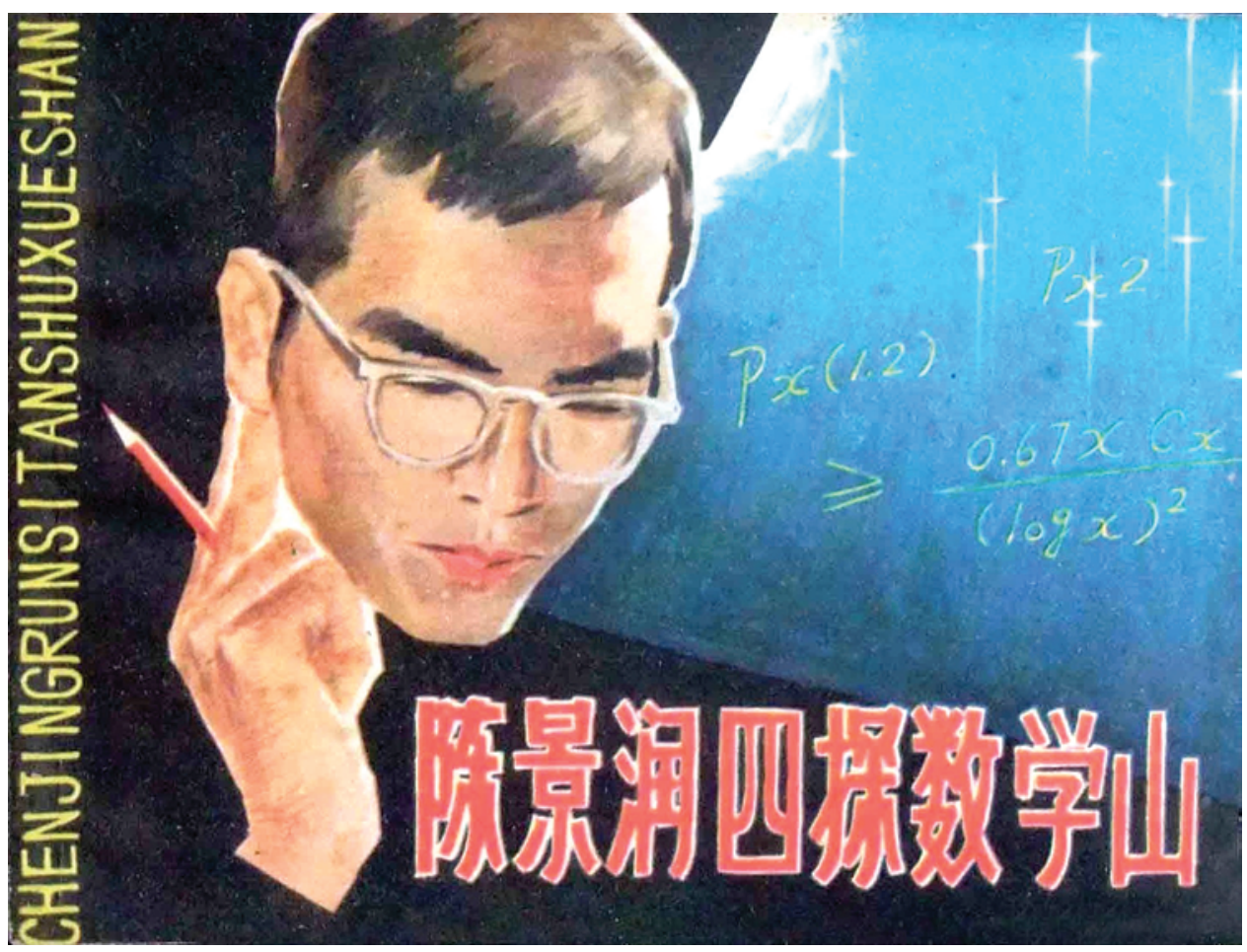

FIG. 5. Photograph showing the front cover of a children's small comic book about Chen's mathematics pursuits ("Chen Jingrun Explores the Mathematics Mountain Four Times") introduced children to the motivation and dedication of Chen. Chen influenced a generation of children to become interested in scientific pursuits. He was even used as an example of dedication in marriage. The book is in the private collection of Dr. Mark C. Preul.

arithmetic progressions." In 1980 he was elected to the Chinese Academy of Sciences.

\section{Brain Trauma and Parkinson's Disease}

In April 1984, at the age of 51 and while working at the Sinica Institute, on the verge of completing a description for the last portion of his solution to Goldbach's conjecture, Chen was riding a bicycle from his house in Beijing to his favorite bookstore, Xinhua Bookstore, when he was hit by a young man also riding a bicycle at high speed. Chen was knocked unconscious and transported to a regional hospital. After treating his severe closed-head injury, doctors became suspicious of an underlying movement disorder that was not explained by his injuries. Chen was diagnosed with Parkinson's disease, which was markedly affecting his cognition. Bad fortune continued for Chen when, just a few months after his discharge, he was pushed by a crowd of people while exiting a bus and fell down, striking his head and again losing consciousness. He had suffered another significant concussive brain injury, this time rendering him a severe invalid.

Recovering much more slowly after his second brain injury, he remained hospitalized for several years without making progress while receiving modern Western medical therapies. Several traditional Chinese medicines had been used for Chen. Only Dendrobium officinale was reported to have helped Chen's symptoms improve. ${ }^{19} \mathrm{D}$. officinale is a symbiotic mycorrhiza plant found mainly in the south of China in the mountains above an altitude of $1600 \mathrm{~m}$. As early as the Eastern Han Dynasty (25-220 AD), people used D. officinale to treat disease. ${ }^{1}$ D. officinale polysaccharides suppress lymphocyte infiltration and apoptosis, and may balance the chaos of proinflammatory cytokines. ${ }^{16,21}$

Treatments within traditional Chinese medicine continued to be sought for Chen. Zhu Zongxiang, professor of the Institute of Biophysics at the Chinese Academy of Sciences, was called in as an authority on classic Chinese meridians. He invented the "312 meridian theory" based on the "312" meridian exercise method. The " 3 " indicates the massage acupoints Neiguan (P6), Hegu (LI 4), and Zusanli (ST 36). Every acupoint is massaged for 5 minutes. The " 1 " is for abdominal respiration and the " 2 " is for squat exercises. Zhu proposed that the meridian system is a multilayer, multifunction, and polymorphic 3D regulation system. He posited that the "312" meridian exercise can activate the meridians distributed along these parts of the body, thereby maintaining health and treating disease.

In traditional Chinese medicine treatment theory, the human body is a complex system connected by a complex network (Fig. 7 left). The network refers to meridians composed of blood vessels, nerves, interstitial fluid, etc. The same disease might cause different imbalances within the body network in different patients. The theory posits that the same pathogenesis might lead to different symptoms in different patients, and the same symptom might be improved with different treatments in different patients. Thus, individualized therapy is necessary for the patient. ${ }^{4-6}$ 

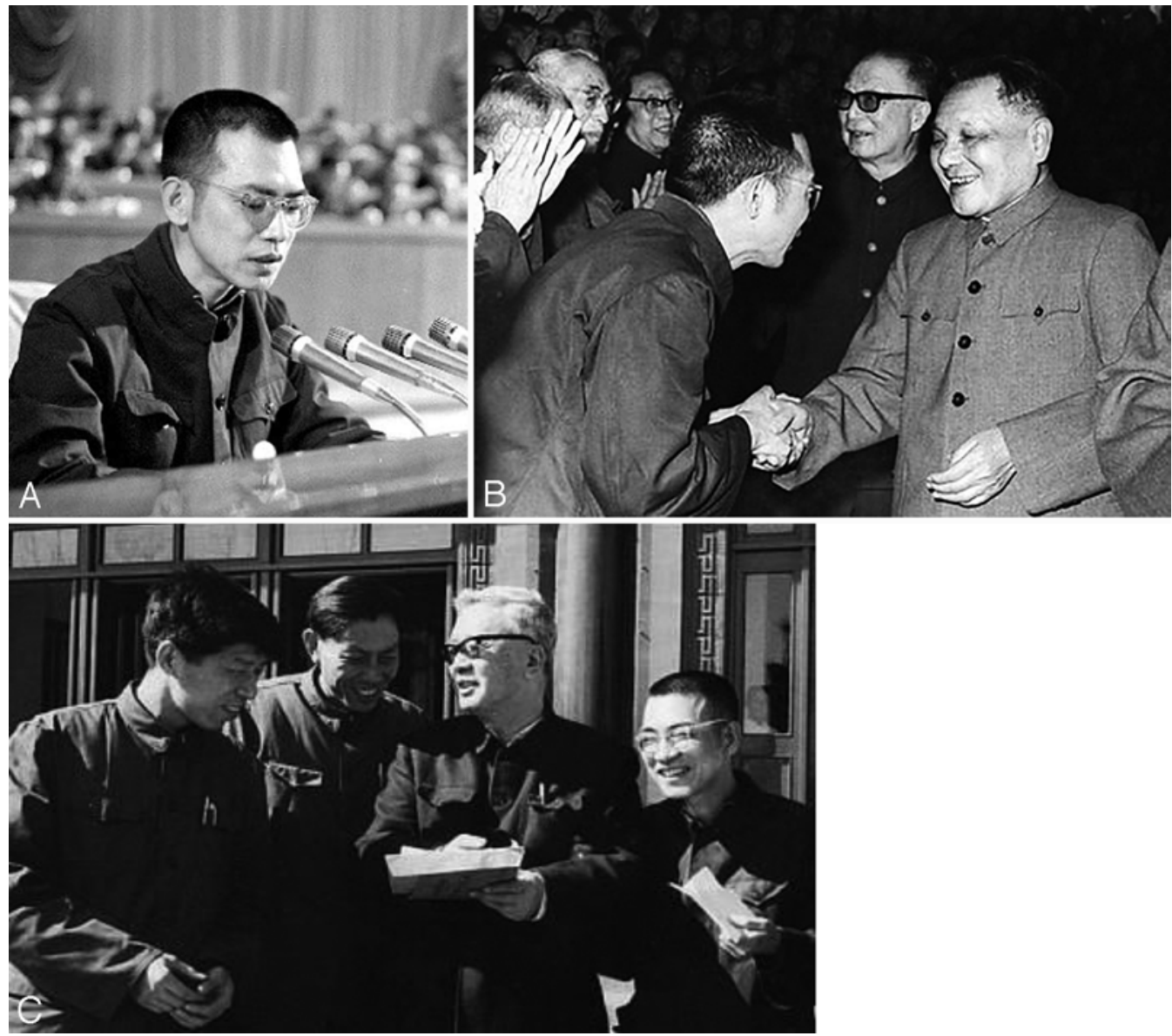

FIG. 6. Photographs of Chen Jingrun. A: Chen addressing the 1978 Chinese National Science Conference. B: Deng Xiaoping (right) congratulating Chen (left). In addition to Deng's major speech at the conference, Premier Hua Guofeng and Vice Premier Fang Yi, the top government figure involved in science and technology, urged that scientists should have freedom to perform research as long as the work was consistent with national priorities. Recently "rehabilitated" senior scientists were integrated with political sponsors having a responsibility for science and technology in the mission to construct ambitious plans for the country. A draft of the "Eight-Year Plan for the Development of Science and Technology," discussed at the 1978 National Science Conference, called for a rapid increase in the number of research workers, for catching up to advanced international levels by the mid-1980s, and for substantial work in such fields as laser science, manned space flight, and high-energy physics. Basic research was to be supported, but applied scientific work was emphasized. C: Hua Lo-Keng (wearing glasses, second from right) and Chen (right) with two other mathematicians outside the 1978 National Science Conference. Note the happy, relaxed expressions, as this photograph was taken after the turmoil caused to academics and scientists who were now relatively free to pursue their interests.

In December 1988, Zhu and Hao Jinkai, another traditional Chinese medicine expert, attempted to help stem the ravaging effects of Parkinson's disease causing Chen's deterioration (Fig. 7 right). Chen was manifesting ongoing severe symptomatology with unsteadiness, limb muscle spasms, loss of eye muscle control, and excess salivation. According to traditional Chinese medicine and meridian theory, the heart is connected to the brain, and thus Zhu and Hao proposed that stimulating the Neiguan acupoint (P6) along the pericardium meridian would activate the pericardium meridian to protect the heart and treat brain disease. Zhu and Hao acupunctured Chen's Neiguan acupoint and provided oxygen therapy for Chen, after which he was able to smile and his ambulation improved. After a year of acupuncture, Chen could control his basic bowel and bladder functions; he also began to walk slowly, and his swallowing and speaking functions improved. ${ }^{24}$
Acupuncture has been used in China to treat diseases for more than 2000 years. ${ }^{13}$ The exact effect of acupuncture on Parkinson's disease remains controversial. Most clinical studies on the efficacy of acupuncture therapy on Parkinson's disease have not shown evidence that acupuncture is an effective treatment ${ }^{14}$ although studies by acupuncture medicine specialists suggest some positive effects of acupuncture therapy on Parkinson's disease, specifically with regard to motor symptom improvement. ${ }^{23}$ The biological mechanisms in Parkinson's disease after acupuncture therapy are postulated to be 1) an increased neurotrophic factor expression in dopaminergic cells, 2) an antioxidative effect and dopaminergic neuron protection, and 3) an antiinflammatory effect and inhibition of dopaminergic cell apoptosis.

With time and after undergoing acupuncture treatments, Chen gradually returned to work. In 1991, after 


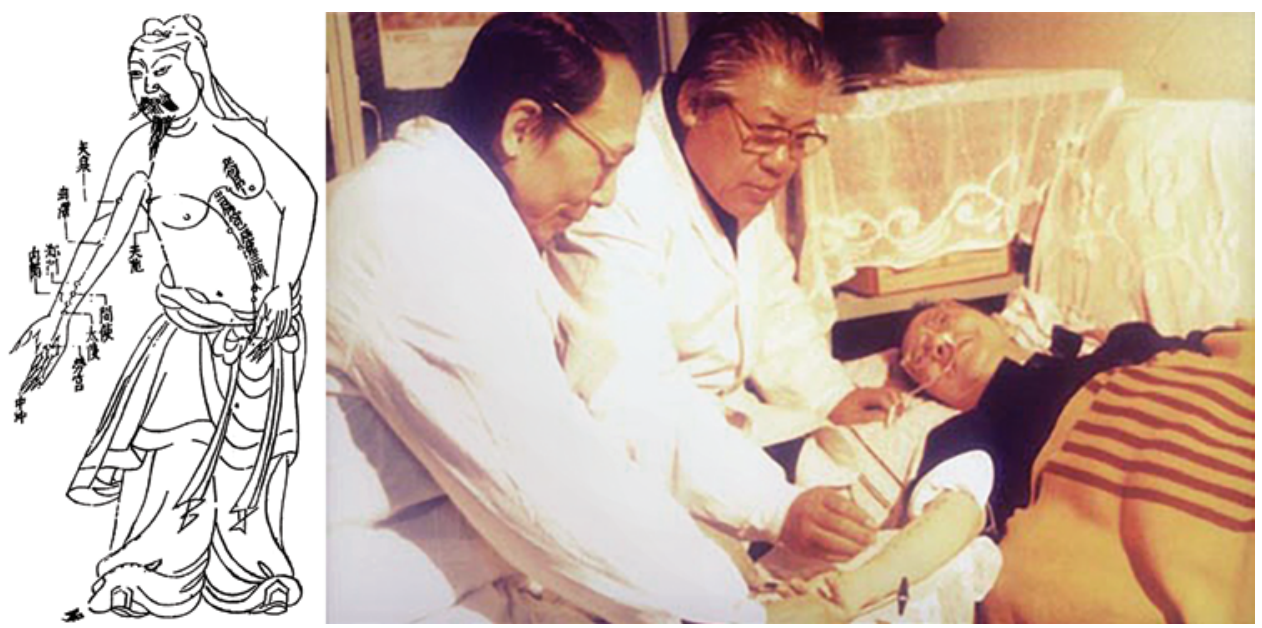

FIG. 7. Left: An acupuncture chart from the Ming Dynasty (1368-1644) showing the meridian network used as a guide to different acupoints for improving different symptoms or treating disease. Source: http://commons.wikimedia.org/wiki/File:Akupunkturkarteming.jpg. Right: Zhu Zongxiang (left) and Hao Jinkai (center) administering acupuncture therapy and oxygen therapy to Chen.

improvement in his Parkinson's disease symptoms, Chen was well enough to vacation in the Changbai Mountains (between China and North Korea; Fig. 8). However, his cognitive deficits were profound. Although Chen's mathematical virtuosity had been taken from him, his former students and associates remained steadfast in the search for a solution to the final portion of Goldbach's conjecture and other prime number progression theory. It is difficult to know with certainty the exact timeline of what would have likely been a landmark publication of Chen's final solution to Goldbach's conjecture. He was certainly very close and probably would have published on it within a few months (1984), judging by the progress he had made and his previous steps that had been defined. Chen appears to have had that unique ability, as many truly remarkable mathematicians do, to visualize the concepts within his mind. Chen's thoughts seemed to enter another dimension. After the brain traumas and Parkinson's onset, such cognitive processes were no longer possible for Chen, and although he was unable to explain the exact mathematical operations, he curiously retained the ability to communicate to his students how he had conducted his searches for clarity and definition.

After 1984, papers were published, albeit with Chen's name, but written by his students who loyally added him as an author. Although Chen was no longer able to perform with complex insight and at his former incredibly high level in mathematics, he remained intimately involved with his students in motivating them to seek solutions to various mathematical problems. Around this same time, Chen completed editing a book titled Youth Math, which was aimed at teaching mathematics to Chinese young people at about the middle or high school level. It was an immensely popular book, stimulating many families and their children to explore the study of mathematics and science.

\section{Commemorations}

Chen died of complications of pneumonia on March 19, 1996, at the age of 63 years. During his life, Chen had published more than 70 academic papers. His contributions to number theory have been singularly praised by fellow mathematicians and academics worldwide. An as-

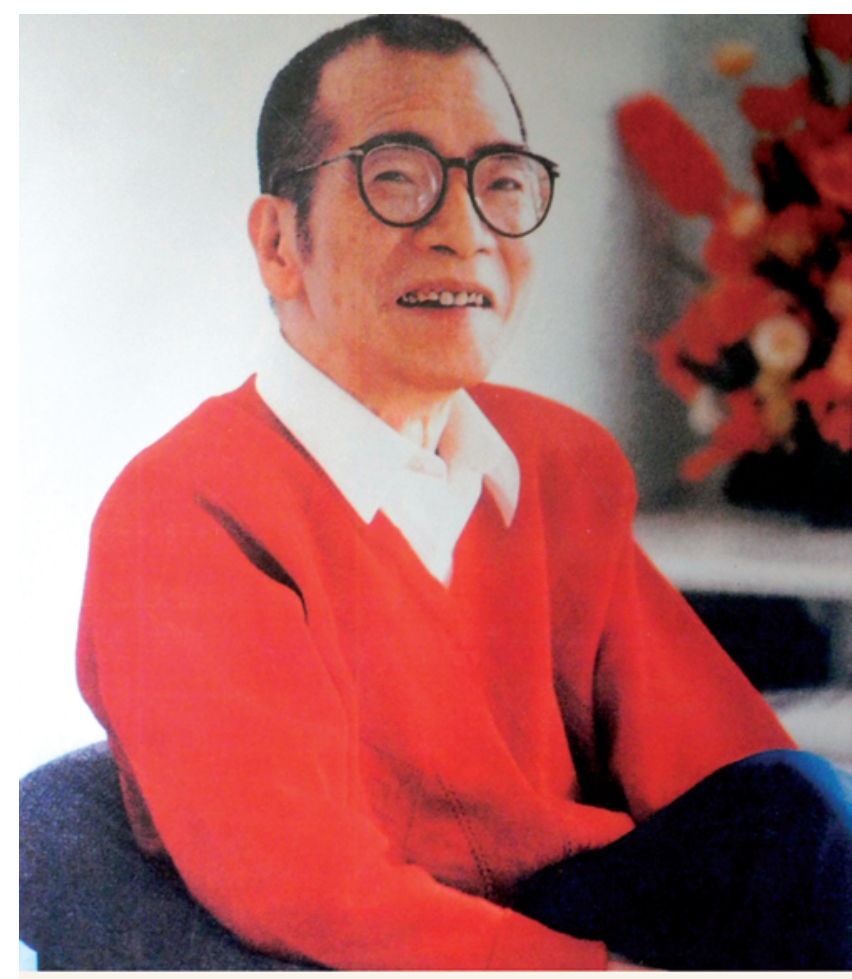

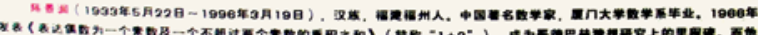

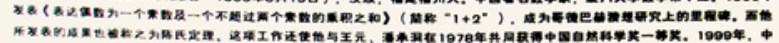
แล

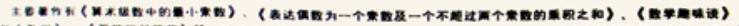
(

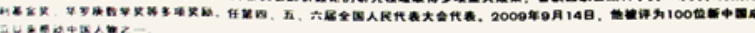

FIG. 8. Photograph of a poster from the early 1990s showing Chen healthy enough to beam his broad smile and containing biographical information printed below. The poster is in the private collection of Dr. Mark C. Preul. 
teroid discovered in 1996 after Chen's death was named 7681Chenjingrun, and in 1999, to honor his achievements China issued a commemorative postcard (Fig. 9 upper) and a postage stamp (Fig. 9 lower) featuring his silhouette and the famed Goldbach inequality.

The famous mathematician André Weil is reported to have stated about Chen: "Each work of Mr. Chen Jingrun seems as if it is scaling the tallest mountains of the Himalayas. It is perilous [work], but if successful, will certainly affect the world." During a Beijing TV interview, Chen said, "My life is dedication, I do not ask for anything."

\section{Conclusions}

Chen Jingrun's life in mathematics was the search for a solution to Goldbach's conjecture. On the doorstep of solving one of the most fundamental and long-lived number
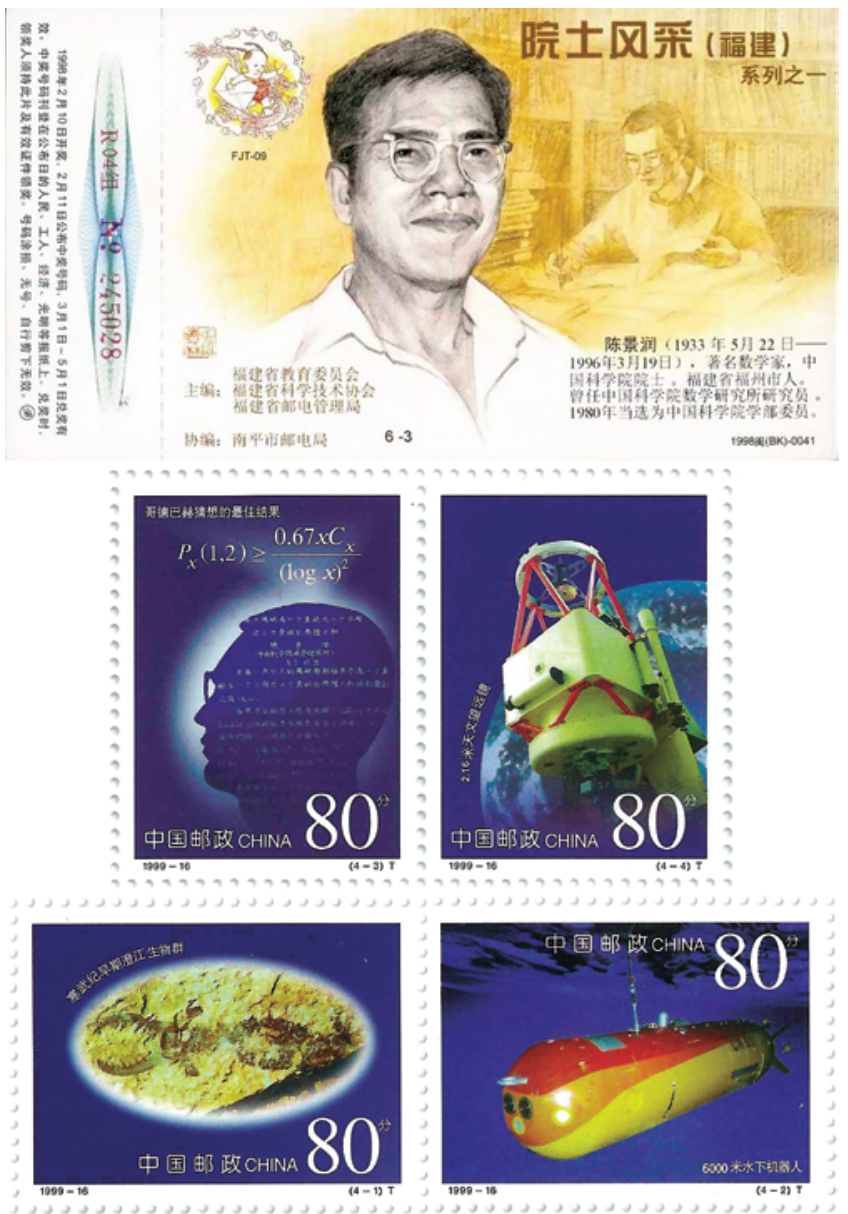

FIG. 9. Upper: In 1998 China issued a postcard honoring Chen's work. The Chinese title on the upper portion of the card translates to "A Noble Academician" and in the lower right corner is brief biographical information. Lower: China issued postage stamps in 1999 commemorating the 50th anniversary of the Chinese Academy of Sciences. There were 4 stamps on 2 sheets, honoring space, undersea exploration, and fossil life, but only 1 person (Chen) was chosen to be individually represented. Chen's head is silhouetted behind his writing with the Chinese characters above the equation translated as "The best result of Goldbach's conjecture." Postcard and stamps are in the private collection of Dr. Mark C. Preul. theory problems, he was unfortunately struck down with severe brain injuries due to trauma and the consequences of Parkinson's disease. Standard neurosurgical care provided little improvement, yet traditional Chinese medical methods affecting the nervous system may have provided him with at least some functional recovery. The conjecture of Goldbach, dealing with fundamental mathematics and prime numbers, is an essential concept that is critical to our knowledge of the progression of numbers. Chen was praised worldwide as the most likely person in the world to completely solve the over 250-year-old Goldbach's conjecture, and his partial description remains the best-known solution to it. Twenty years after Chen's death, a full solution to Goldbach's conjecture remains elusive. Chen remained true to the primary goal of mathematics, the search for absolute clarity. Ironically surviving some of the most brutal experiences over the course of his lifetime, and despite being deprived at the very peak of his genius, Chen, supported by his wife, became a symbol of dedication, perseverance, and motivation to his students and associates, to Chinese youth, to a nation, and to mathematicians and scientists throughout the world.

\section{Acknowledgments}

We are grateful to the staff of Neuroscience Publications at Barrow Neurological Institute, especially to Jaime-Lynn Canales and Cassandra Todd for help with the figures and to Samantha Soto for editorial support. We thank Ken Brooks for his assistance with language review. Dr. Shuyuan Hong, a traditional Chinese acupuncture therapist, contributed knowledge on traditional Chinese medicine and acupuncture therapy. We are grateful to Li Zhensheng, the foremost photographer of the Chinese Cultural Revolution, and Jeffrey D. Smith of Contact Press Images for contributing extraordinary photographs. We thank Yuan Zhu who assisted with the acquisition of objects related to the life of Chen Jingrun. This project was supported in part by funds from the Newsome Family Endowed Chair in Neurosurgery Research held by Dr. Preul.

\section{References}

1. Cai GX, Li J, Li SX, Huang D, Zhao XB: Applications of Dendrobium officinale in ancient and modern times. J Tradit Chin Med 31:77-81, 2011

2. Caldwell CK: Goldbach's conjecture. The Prime Pages. (http://primes.utm.edu/glossary/page.php?sort=gold bachconjecture) [Accessed April 25, 2016]

3. Cao C: Science imperiled: intellectuals and the Cultural Revolution, in Wei CN, Brock DE (eds): Mr. Science and Chairman Mao's Cultural Revolution, Science and Technology in Modern China. Lanham, MD: Lexington Books, 2013

4. Chang S: The meridian system and mechanism of acupuncture-a comparative review. Part 1: the meridian system. Taiwan J Obstet Gynecol 51:506-514, 2012

5. Chang S: The meridian system and mechanism of acupuncture-a comparative review. Part 2: mechanism of acupuncture analgesia. Taiwan J Obstet Gynecol 52:14-24, 2013

6. Chang S: The meridian system and mechanism of acupuncture-a comparative review. Part 3: mechanisms of acupuncture therapies. Taiwan J Obstet Gynecol 52:171-184, 2013

7. Chen JR: [On the representation of a large even integer as the sum of a prime and the product of at most two primes.] $\mathbf{J}$ Kexue Tongbao 17:385-386, 1966 (Chinese)

8. Chen JR: On the representation of a large even integer as the sum of a prime and a product of at most two primes. Sci Sin 16:157-176, 1973 
9. Chengtong P, Yuan W: Chen Jingrun: a brief outline of his life and works. Acta Math Sin Engl Ser 12:225-233, 1996

10. Cullen C (ed): Science and Civilisation in China. Cambridge: Cambridge University Press, 1954-2000

11. Dickson LE: Goldbach's empirical theorem: every integer is a sum of two primes, in History of the Theory of Numbers. New York: Dover, 2005, Vol 1

12. Elvin M: The Pattern of the Chinese Past. Stanford, CA: Stanford University Press, 1973

13. Hsieh CL: Acupuncture as treatment for nervous system diseases. BioMedicine 2:51-57, 2012

14. Kim HJ, Jeon BS: Is acupuncture efficacious therapy in Parkinson's disease? J Neurol Sci 341:1-7, 2014

15. Kwok-sing L (ed): A Glossary of Political Terms of the People's Republic of China. Lok M, trans. Hong Kong: The Chinese University Press, 1995

16. Lin X, Shaw PC, Sze SC, Tong Y, Zhang Y: Dendrobium officinale polysaccharides ameliorate the abnormality of aquaporin 5, pro-inflammatory cytokines and inhibit apoptosis in the experimental Sjögren's syndrome mice. Int Immunopharmacol 11:2025-2032, 2011

17. Liu D: A brief introduction to the studies on history of science in the People's Republic of China. Institute for the History of Natural Science. (http://wwwl.ihns.ac.cn/ members/liu/doc/chinese.htm) [Accessed April 25, 2016]

18. Macfarquhar R, Schoenhals M: Mao's Last Revolution. Boston: Harvard University Press, 2006

19. Wangjiwang: [Mathematician Chen Jingrun and Dendrobium officinale.] (http://www.wangjiwang.com/memorial/ memorial_shc.aspx?id=7049) [Accessed April 25, 2016] (Chinese)

20. Weisstein EW: Goldbach conjecture. Wolfram Mathworld. (http://mathworld.wolfram.com/GoldbachConjecture.html) [Accessed April 20, 2016]
21. Xiang L, Stephen Sze CW, Ng TB, Tong Y, Shaw PC, Sydney Tang CW, et al: Polysaccharides of Dendrobium officinale inhibit TNF- $\alpha$-induced apoptosis in A-253 cell line. Inflamm Res 62:313-324, 2013

22. Xu C: Goldbach's conjecture. People's Literature 1:53-68, 1978

23. Zeng BY, Salvage S, Jenner P: Current development of acupuncture research in Parkinson's disease. Int Rev Neurobiol 111:141-158, 2013

24. Zongxiang Z: [Prof. Zhu made a treatment for mathematician Chen Jingrun.] Jiankang312. (http://www.312bjk.com/index. php?_m=mod_static\&_a=view\&sc_id=8) [Accessed April 25, 2016] (Chinese)

\section{Disclosures}

Dr. Preul has received clinical or research support for the study from Barrow Neurological Foundation, the Women's Board of the Barrow Neurological Institute, and the Newsome Family Endowment in Neurosurgery.

\section{Author Contributions}

Conception and design: Preul, Lei. Drafting the article: Lei, Dru. Critically revising the article: all authors. Reviewed submitted version of manuscript: all authors. Approved the final version of the manuscript on behalf of all authors: Preul. Administrative/ technical/material support: Preul, Lei, Belykh, Elhadi.

\section{Correspondence}

Mark C. Preul, c/o Neuroscience Publications, Barrow Neurological Institute, St. Joseph's Hospital and Medical Center, 350 W Thomas Rd., Phoenix, AZ 85013. email: neuropub@ dignityhealth.org. 